EXTENDED REPORT

\title{
When a DMARD fails, should patients switch to sulfasalazine or add sulfasalazine to continuing leflunomide?
}

\author{
M Dougados, P Emery, E M Lemmel, C A F Zerbini, S Brin, P van Riel
}

See end of article for authors' affiliations

\section{Correspondence to:} Professor M Dougados, René Descartes University Hôpital Cochin, 27, Rue du Faubourg Saint-Jacques, 75679 Paris Cedex 14, France; maxime.dougados@ cch.ap-hop-paris.fr

Accepted 27 April 2004 Published Online First 22 July 2004
Objective: To evaluate the efficacy and safety of adding sulfasalazine to leflunomide treatment compared with switching to sulfasalazine alone in patients with RA with an inadequate response to leflunomide monotherapy.

Methods: Patients with active RA ((DAS28) >3.2) who were enrolled in the first open label phase of the RELIEF study received leflunomide for 24 weeks. Inadequate responders then entered the double blind phase and received a further 24 weeks' treatment with leflunomide (20 mg once daily) plus sulfasalazine (final dose $2 \mathrm{~g}$ once daily), or placebo plus sulfasalazine (dose as above). The primary efficacy variable was the DAS28 response rate, and secondary efficacy outcomes were ACR 20\%, 50\%, and 70\% response rates. Adverse events, including standard laboratory tests, were recorded.

Results: 106 inadequate responders entered the double blind phase; 56 received leflunomide plus sulfasalazine, and 50 placebo plus sulfasalazine. In the intention to treat population, more patients receiving leflunomide plus sulfasalazine $(25 / 56(45 \%))$ achieved a DAS28 response than those receiving placebo plus sulfasalazine $(17 / 50(34 \%))(p=0.179)$. In week 24 completers, more patients receiving leflunomide plus sulfasalazine (17/56 (30\%)) were DAS28 responders than those receiving placebo plus sulfasalazine (10/50 (20\%)) ( $p=0.081)$. Comparable numbers in each group were ACR $20 \%$ responders; the ACR $50 \%$ response rate was significantly higher in the leflunomide plus sulfasalazine group (8.9\%) than in the placebo plus sulfasalazine group $(0 \%)(p=0.038)$. The safety profiles of both groups were comparable.

Conclusion: Patient numbers are small and firm conclusions cannot be reached, but a non-significant benefit is indicated for combining leflunomide with sulfasalazine compared with switching to sulfasalazine alone in patients inadequately responding to leflunomide.
$\mathrm{T}$ he aim of current rheumatoid arthritis (RA) treatment is to control disease activity, alleviate symptoms, maintain physical function, optimise quality of life, slow the rate of joint damage and, ideally, induce complete remission. ${ }^{1}$ Disease modifying antirheumatic drugs (DMARDs) have the potential to minimise or prevent joint damage while preserving joint integrity and physical function. It is now recognised that irreversible joint damage and erosions occur early, within the first 2 years of the disease process, ${ }^{2}$ and so to prevent this, early initiation of DMARDs is recommended. ${ }^{3} \mathrm{~A}$ recent meta-analysis has confirmed the clinical benefit of starting DMARD treatment early in patients with RA. However, patient discontinuations of a drug owing to a lack of efficacy or related toxicity limit the long term use of currently available DMARDs.

Leflunomide is a new DMARD that selectively inhibits de novo pyrimidine synthesis by blocking the rate limiting enzyme dihydro-orotate dehydrogenase, ${ }^{5}$ thereby preventing DNA synthesis. ${ }^{6-8}$ The efficacy and safety of leflunomide in patients with active RA have been demonstrated for up to 2 years, in three phase III studies. ${ }^{9-14}$ Leflunomide was shown to be better than placebo and at least as effective as sulfasalazine and methotrexate in improving individual signs and symptoms of $\mathrm{RA}^{9-11}$; these responses were seen as early as 4 weeks and were maintained for up to 2 years. ${ }^{9-12} 14$ Leflunomide was also effective in slowing disease progression as assessed by radiographic analysis of joint damage, ${ }^{13}{ }^{15}$ and in improving functional activity as measured by the Stanford Health Assessment Questionnaire Disease Activity Index . ${ }^{12} 14$ More recently, an open label extension study of patients treated with leflunomide demonstrated that these improvements are maintained for up to 5 years in a subset of patients, with no new or unexpected adverse events emerging compared with the initial phase III studies. ${ }^{16}$

Despite the proven benefits of leflunomide, some patients fail to respond to this treatment and the most appropriate course of action for these patients remains to be established. Studies have demonstrated that adding a second disease modifying agent to an ineffective DMARD is more effective than continuing the ineffective DMARD alone. ${ }^{17-21}$ A recent study investigating the safety and efficacy of adding leflunomide to continuing doses of methotrexate demonstrated clinical benefits without an increase in the incidence of adverse events compared with the addition of placebo. ${ }^{22}$ Furthermore, it has been shown in an open label study in 40 patients with RA that adding methotrexate to continuing sulfasalazine in patients for whom sulfasalazine fails was more effective than switching to methotrexate alone. ${ }^{23}$

RELIEF (Rheumatoid arthritis Evaluation of Leflunomide further Insights into its Efficacy) is a 48 week, multicentre, international study that consists of two phases. The first phase evaluated the efficacy and safety of leflunomide in a

Abbreviations: ACR, American College of Rheumatology; ALT, alanine aminotransferase; DAS28, 28 joint count Disease Activity Score; DMARD, disease modifying antirheumatic drug; ESR, erythrocyte sedimentation rate; ITT, intention to treat; LOCF, last observation carried forward; PMN, polymorphonuclear; RA, rheumatoid arthritis; RELIEF, Rheumatoid arthritis Evaluation of Leflunomide further Insights into its Efficacy; RF, rheumatoid factor; ULN, upper limit of normal 


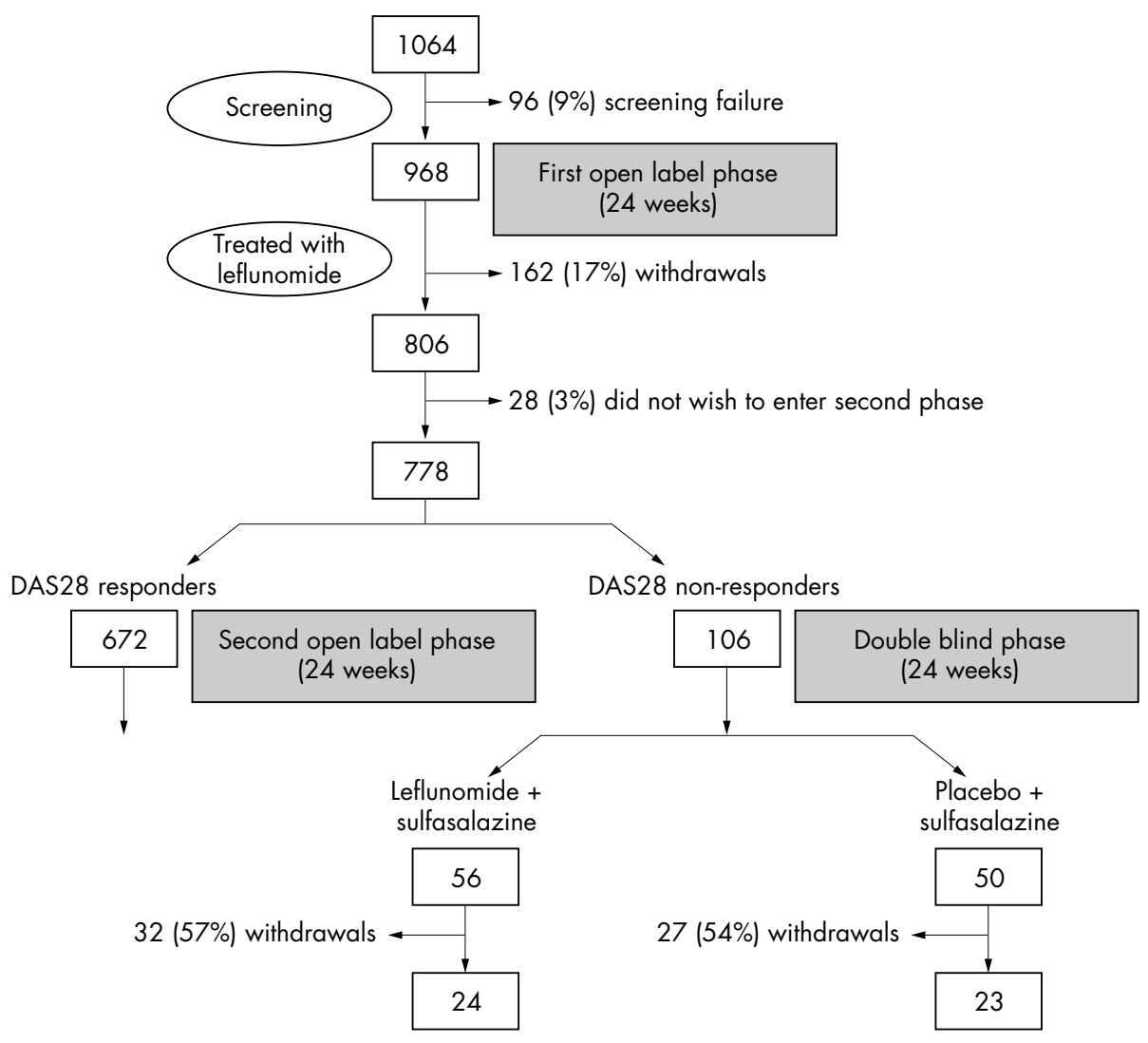

Figure 1 RELIEF study design.

24 week, open label study in a setting close to daily clinical practice. ${ }^{24}$ In the second phase of the study, patients who were good or moderate responders to leflunomide treatment (according to the 28 joint count Disease Activity Score (DAS28) criteria) continued leflunomide treatment for a further 24 weeks in a second open label phase. Patients who did not adequately respond to leflunomide entered a double blind phase-a 24 week, randomised, double blind, placebo controlled study to compare the efficacy and safety of adding sulfasalazine to leflunomide with switching to sulfasalazine alone. The results of this 24 week, double blind phase are presented here.

\section{PATIENTS AND METHODS Patients}

Male or female patients aged 18-75 years with active RA as defined by a DAS28 $>3.2$, and with a functional classification of I, II, or III according to the American Rheumatology Association criteria, were included in the main study. Patients of American Rheumatology Association functional class IV were not eligible for inclusion. Women of childbearing potential and men were required to use adequate contraception throughout the study. Women who were pregnant or breast feeding were excluded. The protocol required treatment with other DMARDs to be discontinued at least 4 weeks before enrolment in the initial phase of the study. Stable doses of non-steroidal anti-inflammatory drugs or oral corticosteroids (maximum daily dose $10 \mathrm{mg}$ prednisone or steroid equivalent) were permitted as concomitant drugs. Intra-articular injections of corticosteroids (maximum dose $60 \mathrm{mg}$ prednisone or equivalent) were to be avoided if possible, and were not permitted within the 4 weeks preceding the assessment. Analgesics were allowed, but were not to be taken in the 6 hours before joint examination. Patients with an inadequate DAS28 response to leflunomide in the initial open label phase of the study were eligible for entry into the double blind phase.

This study was conducted in accordance with the principles of the good clinical practice guidelines of the European Community and the Declaration of Helsinki. The clinical study protocol and study related documents were approved by an independent ethics committee. Written, informed consent to enter the study was required from patients.

\section{Study design}

This was a 24 week, double blind phase of the multicentre, international RELIEF study, which followed an initial 24 week open label phase (fig 1). The study was carried out in 162 centres in 14 countries across Europe, South America, Australia, and New Zealand. In the initial open label phase of the study, after a 1-2 week screening period and interruption of any other DMARD for at least a month, patients received a leflunomide loading dose of $100 \mathrm{mg}$ once daily for the first 3 days followed by a maintenance dose of $20 \mathrm{mg}$ once daily thereafter. Patients who were non-responders to leflunomide at the end of the first open label phase were randomly allocated to a further 24 weeks' treatment with either leflunomide (20 mg once daily) plus sulfasalazine (2 g once daily starting at $0.5 \mathrm{~g}$ increasing in weekly steps of $0.5 \mathrm{~g}$ ) or sulfasalazine (dose as above) plus placebo in the second double blind phase of the study. Patients who were good or moderate responders in the first open label phase entered a second open label phase of 24 weeks leflunomide monotherapy, the results of which will be presented elsewhere.

\section{Efficacy}

The primary efficacy variable was change in disease activity assessed by the EULAR criteria using the DAS28 score. ${ }^{25}$ This was analysed at 4 week intervals up to the end point (week 
Table 1 Baseline characteristics (before entry to the first open label phase) of 969 patients and a comparison of all patients with the patients continuing to the second open phase $(n=672)$ and those entering the double blind phase $(n=106)$

\begin{tabular}{|c|c|c|c|c|}
\hline \multirow[b]{2}{*}{ Characteristics } & \multirow{2}{*}{$\begin{array}{l}\begin{array}{l}\text { First open label } \\
\text { phase }\end{array} \\
\begin{array}{l}\text { Leflunomide } \\
(\mathrm{n}=969)\end{array}\end{array}$} & \multirow{2}{*}{$\begin{array}{l}\text { Second open } \\
\text { label phase } \\
\\
\text { Leflunomide } \\
\text { (n=672) }\end{array}$} & \multicolumn{2}{|c|}{ Second double blind phase } \\
\hline & & & $\begin{array}{l}\text { Leflunomide + } \\
\text { sulfasalazine } \\
(\mathrm{n}=56 \text { ) }\end{array}$ & $\begin{array}{l}\text { Placebo + } \\
\text { sulfasalazine } \\
\text { ( } n=50 \text { ) }\end{array}$ \\
\hline Mean age (years) & 55.0 & 54.8 & 56.3 & 55.4 \\
\hline Female, No (\%) & $722(74.5)$ & $503(74.9)$ & $37(66.1)$ & $37(74.0)$ \\
\hline \multicolumn{5}{|l|}{ Disease duration: } \\
\hline Mean (years) & 7.25 & 7.4 & 6.2 & 6.1 \\
\hline Diagnosed $>2$ years $(\%)$ & 61.4 & 63.5 & 55.4 & 54.0 \\
\hline \multicolumn{5}{|l|}{ Disease activity: } \\
\hline ARA functional class I (\%) & 12.3 & 12.913 & 7.1 & 10.0 \\
\hline ARA functional class II/III (\%) & 87.7 & 87.1 & 92.9 & 90.0 \\
\hline DAS28 & & 0.7 & 12.5 & \\
\hline Low activity & - & - & - & - \\
\hline Moderate activity & 13.5 & 13.7 & 12.5 & 10.2 \\
\hline High activity & 86.5 & 86.3 & 87.5 & 92.0 \\
\hline Mean DAS28 score & 6.3 & 6.3 & 6.2 & 6.3 \\
\hline Rheumatoid factor positive (\%) & 82.7 & 82.1 & 77.8 & 78.0 \\
\hline \multicolumn{5}{|l|}{ Pharmacological treatment: } \\
\hline Previous DMARD treatment (\%) & 72.1 & 73.5 & 66.1 & 68.0 \\
\hline Mean number of previous DMARDs & 1.8 & 1.9 & 1.7 & 1.3 \\
\hline
\end{tabular}

24 or last observation carried forward (LOCF)). The DAS28 score was calculated using the formula:

$$
\text { DAS28 }=0.56 \sqrt{\mathrm{TJC}}+0.28 \sqrt{\mathrm{SJC}}+0.70 \mathrm{ln} \mathrm{ESR}+0.014 \mathrm{GH}
$$

where TJC is tender joint count (out of 28 assessed joints), SJC is swollen joint count (out of 28 assessed joints), ESR is erythrocyte sedimentation rate, and GH is a general health score as assessed by the patient on a $100 \mathrm{~mm}$ visual analogue scale. According to the EULAR criteria, remission was defined as a DAS28 score of $<2.6$ and a good response as a significant change $(>1.2)$ and low disease activity at the end point (DAS28 $\leqslant 3.2$ ). A moderate response was defined as a significant change $(>1.2)$ and moderate or high disease activity at the end point (DAS28 $>3.2$ ), or a change $\leqslant 1.2$ and $>0.6$ and low or moderate disease activity at the end point (DAS28 $\leqslant 5.1$ ). The DAS28 response rate is the sum of the good and moderate responders. "Sustained" responders by DAS28 criteria were those achieving a response that was sustained until week 24 .

The secondary efficacy variables were response rate according to American College of Rheumatology (ACR) $20 \%$, ACR $50 \%$, and ACR $70 \%$ criteria at 4 week intervals and the end point (week 24 or LOCF). ${ }^{26}$ The ACR 20\% responder rate indicates the proportion of patients showing a $20 \%$ improvement from baseline levels in tender and swollen joint counts, and a 20\% improvement in three of the following five criteria: investigator's global assessment; patient's global assessment; pain intensity assessment; functional disability index (using the Health Assessment Questionnaire); and C reactive protein or ESR. The ACR 50\% and ACR $70 \%$ response rates were similarly defined, taking into account $50 \%$ and $70 \%$ improvements, respectively. The individual variables of the ACR criteria, duration of morning stiffness, and rheumatoid factor (RF) levels were also measured.

The ACR $20 \%, 50 \%$, and $70 \%$ response rates were calculated for week 24 completers. "Sustained" responders by ACR criteria were those achieving a response that was sustained until week 24 .

\section{Safety}

Safety was monitored by physical examination, vital signs, clinical laboratory measurements, electrocardiograms, and chest $x$ ray data. All adverse events reported by patients or

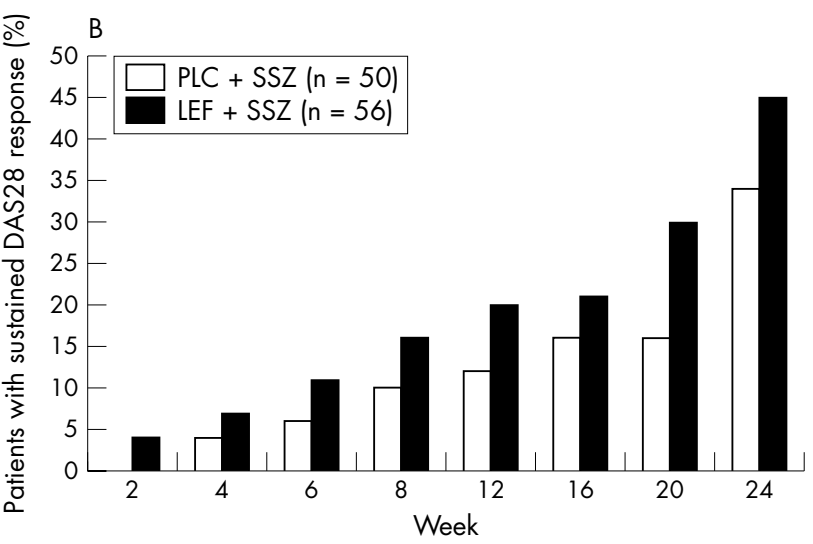

Figure 2 Expected and observed DAS28 response rates at the end of the study (week 24 or LOCF) and DAS28 response rates for week 24 completers (A) and sustained DAS28 responders by study visit (B). LEF, leflunomide; SSZ, sulfasalazine; PLC, placebo. 
observed or elicited through questioning by the investigator were also documented. Blood pressure was measured at 4 week intervals in the supine position after a 5 minute rest. Hypertension was reported in the same way as the other adverse events. An a posteriori analysis of blood pressure variables was performed, in which abnormal values were defined as diastolic blood pressure $>90 \mathrm{~mm} \mathrm{Hg}$ or systolic blood pressure $>160 \mathrm{~mm} \mathrm{Hg}$ on at least two consecutive visits during the treatment period. Standard laboratory analyses were carried out at 4 week intervals. Patients with liver function test abnormalities, as defined by serum alanine aminotransferase (ALT) levels $\geqslant 5 \times$ upper limit of normal (ULN), stopped treatment. Patients with ALT levels $\geqslant 3 \times$ ULN and $<5 \times$ ULN continued to receive treatment, the measurement of these enzymes being repeated within 1 week, and patients stopped treatment if ALT persisted between $3 \times$ ULN and $5 \times$ ULN. Patients with polymorphonuclear neutrophil (PMN) counts $<1 \times 10^{9} / 1$ or signs of infection stopped treatment. Patients with PMN counts of $\geqslant 1 \times 10^{9} / 1$ and $<1.5 \times 10^{9} / 1$ continued to receive treatment, with the measurement of these blood cell counts being repeated within 1 week; patients discontinued treatment if PMN counts persisted between $1 \times 10^{9} / 1$ and $1.5 \times 10^{9} / 1$. No dose adjustments were permitted.

\section{Sample size calculation}

Before initiation of the RELIEF study, it was calculated that 795 patients would need to be enrolled in the initial open label phase of the study to enable adequate patient numbers to show significant differences between arms in the double blind phase of the study. This was based on an assumed withdrawal rate of $25 \%$ in the first open label phase and a predicted $50 \%$ DAS2 8 response rate at the end of this first phase. These sample size calculations were based on the 146 patients required for each double blind treatment group (total 292 patients) to show expected DAS28 response rates of $50 \%$ for the leflunomide plus sulfasalazine group and 35\% for the placebo plus sulfasalazine group (one sided test). This also allowed for a non-evaluability rate of $2 \%$, such that 298 patients would need to be randomised to the double blind phase.

\section{Statistical analysis}

Descriptive statistics were used to describe demographics and baseline characteristics. Efficacy analyses were performed primarily on the intention to treat (ITT) population- that is, all included patients who received the study drug with at least one evaluation. If a patient dropped out before the end of the study through toxicity or lack of efficacy, data from the last observation was carried forward (LOCF). A secondary population analysed for efficacy was the week 24 completers, including all patients who completed 24 weeks of treatment in the double blind phase plus those who withdrew from the study who had a treatment duration greater than 160 days and an evaluation for all visits. Changes from baseline in the individual components of the ACR criteria, RF levels, and duration of morning stiffness were presented as mean (standard deviation). Safety measures were performed on the ITT population. Treatment group comparisons of continuous variables were made with Student's $t$ test or Wilcoxon's rank sum test, and with Fischer's exact test for discrete variables.

\section{RESULTS}

\section{Patients and study course}

Of the 968 patients treated in the first open label phase of RELIEF, 806 completed 24 weeks' leflunomide treatment and 778 continued in the second phase of the trial. Only 106/778 (13.6\%) were classified as inadequate responders according to the DAS28 criteria and, therefore, entered the double blind phase. This number of patients was lower than calculated to be needed to demonstrate statistically significant differences between groups and was a result of the better than expected response to leflunomide in the first open label phase. Of these 106 patients, 56 were randomised to leflunomide plus sulfasalazine and 50 to placebo plus sulfasalazine (no prior washout procedure was used). At baseline, the characteristics of patients in the two treatment groups were similar (table 1). The mean age of patients in the leflunomide plus sulfasalazine group was 56.3 years and $66.1 \%$ were female, compared with 55.4 years and $74.0 \%$ in the placebo plus sulfasalazine group. The disease duration in the leflunomide plus sulfasalazine group and placebo plus sulfasalazine group was 6.2 years and 6.1 years, respectively, and $66.1 \%$ and $68.0 \%$, respectively, had used previous DMARD treatment. The mean DAS28 score was 6.15 in the leflunomide plus sulfasalazine group and 6.25 in the placebo plus leflunomide group. Furthermore, the baseline demographics of the 106 patients entering the double blind phase were similar to those seen at baseline in the 968 patients receiving leflunomide in the first open label phase of the study (table 1).

A total of 59/106 (56\%) patients stopped treatment before the end of the study; $32 / 56$ (57\%) patients in the leflunomide plus sulfasalazine group $(26(46 \%)$ owing to an adverse
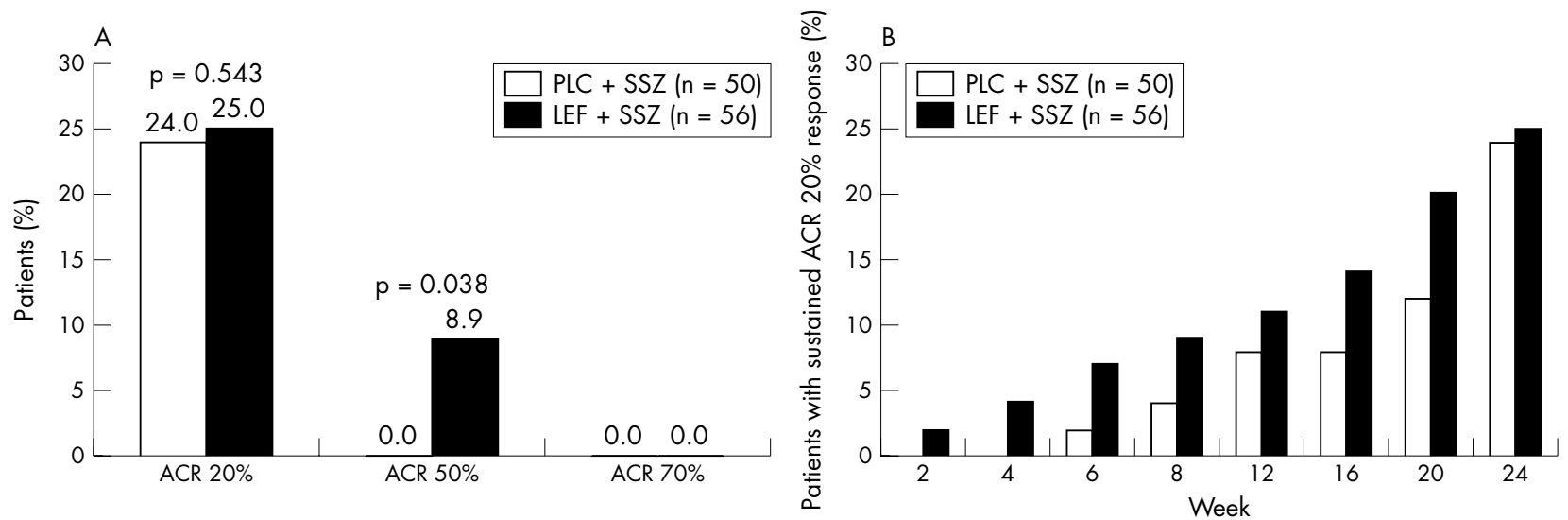

Figure 3 ACR 20\%,50\%, and 70\% responses at the end of the study (week 24 or LOCF) (A) and sustained ACR 20\% responders by study visit (B). LEF, leflunomide; SSZ, sulfasalazine; PLC, placebo. 
Table 2 Changes in individual measures of the ACR response

\begin{tabular}{|c|c|c|c|c|c|c|c|}
\hline \multirow[b]{2}{*}{ ACR criteria [mean (SD)] } & \multicolumn{3}{|c|}{ Leflunomide + sulfasalazine $(n=56)$} & \multicolumn{3}{|c|}{ Placebo + sulfasalazine $(n=50)$} & \multirow[b]{2}{*}{ p Value ${ }^{*}$} \\
\hline & $\begin{array}{l}\text { Baseline } \\
\text { (week 24) }\end{array}$ & $\begin{array}{l}\text { End point } \\
\text { (week 48) }\end{array}$ & $\begin{array}{l}\text { Change from } \\
\text { baseline }\end{array}$ & $\begin{array}{l}\text { Baseline } \\
\text { (week 24) }\end{array}$ & $\begin{array}{l}\text { End point } \\
\text { (week 48) }\end{array}$ & $\begin{array}{l}\text { Change from } \\
\text { baseline }\end{array}$ & \\
\hline TJC & $12.36(7.35)$ & $9.68(8.20)$ & $-2.68(6.37)$ & $13.92(7.20)$ & $12.52(8.45)$ & $-1.40(6.93)$ & 0.09 \\
\hline SJC & $9.84(6.94)$ & $8.34(6.86)$ & $-1.50(4.84)$ & $10.82(6.02)$ & $10.06(7.36)$ & $-0.76(5.72)$ & 0.39 \\
\hline $\operatorname{ESR}\left(\mathrm{mm} / 1^{\text {st }} \mathrm{h}\right)$ & $43.20(24.91)$ & $38.32(25.53)$ & $-4.88(25.65)$ & $41.54(25.03)$ & $36.12(24.93)$ & $-5.42(21.50)$ & 0.38 \\
\hline CRP $(\mathrm{mg} / \mathrm{l})$ & $24.15(28.00)$ & 19.05 (20.93) & $-4.87(26.60)$ & $22.60(25.68)$ & $25.88(31.40)$ & $+3.28(28.31)$ & 0.40 \\
\hline Pain intensity assessment ( $\mathrm{mm}$ ) & $50.27(23.69)$ & $41.05(26.85)$ & $-9.21(24.91)$ & $49.92(22.09)$ & $41.60(24.41)$ & $-8.32(21.74)$ & 0.4292 \\
\hline Functional disability indext & $1.29(0.69)$ & $1.18(0.72)$ & $-0.11(0.38)$ & $1.39(0.64)$ & $1.36(0.65)$ & $-0.03(0.39)$ & - \\
\hline $\mathrm{HAQ}$ score‡ & $1.08(0.63)$ & $0.99(0.65)$ & $-0.09(0.32)$ & $1.16(0.60)$ & $1.14(0.61)$ & $-0.02(0.36)$ & - \\
\hline
\end{tabular}

*One sided p value; placebo + sulfasalazine versus leflunomide + sulfasalazine; the functional disability index is based on the sum of the highest scores for each category, divided by the number of categories scored; tthe $\mathrm{HAQ}$ score represents sum of the mean scores for each category, divided by the number of categories.

SD, standard deviation; TJC, tender joint count; SJC, swollen joint count; ESR, erythrocyte sedimentation rate; CRP, C reactive protein; HAQ, Health Assessment Questionnaire.

event, $3(5 \%)$ because of lack of efficacy, and $3(5 \%)$ who did not wish to continue), and $27 / 50(54 \%)$ patients in the placebo plus sulfasalazine group (18 (36\%) owing to an adverse event, $4(8 \%)$ because of lack of efficacy, and 5 (10\%) who did not wish to continue).

\section{Efficacy}

At the end of the study in the ITT population with LOCF, 25/ $56(45 \%)$ patients in the leflunomide plus sulfasalazine group were classified as DAS28 responders compared with 17/50 (34\%) patients in the placebo plus sulfasalazine group $(\mathrm{p}=0.179)$ (fig 2A). In the leflunomide plus sulfasalazine group, $5 / 56(9 \%)$ and 20/56 (36\%) patients were good and moderate responders, respectively, compared with 5/50 (10\%) and $12 / 50(24 \%)$ patients in the placebo plus sulfasalazine group. The mean DAS28 score decreased from baseline to the end point by -0.7 (1.4) in the leflunomide plus sulfasalazine group, and by $-0.6(1.3)$ in the placebo plus sulfasalazine group.

Similar numbers of patients in each group completed 24 weeks' double blind treatment: 24/56 (43\%) patients in the leflunomide plus sulfasalazine group and 23/50 (46\%) patients in the placebo plus sulfasalazine group. Of these week 24 completers, 17/56 (30\%) patients in the leflunomide plus sulfasalazine group were DAS28 responders compared with $10 / 50(20 \%)$ patients in the placebo plus sulfasalazine group, a non-significant difference $(\mathrm{p}=0.081)$ (fig $2 \mathrm{~A}$ ).
There was a progressive increase in the proportion of patients in both treatment groups who were classed as sustained responders-that is, they had a response according to DAS28 criteria that was maintained at the end of the study (fig 2B). At week 2, 2/56 (4\%) patients in the leflunomide plus sulfasalazine group and no patients in the placebo plus sulfasalazine group had a sustained response. At the end of the study (week 24 or LOCF), the number of patients in each group with a sustained response increased to $25 / 56(45 \%)$ in the leflunomide plus sulfasalazine group and 17/50 (34\%) in the placebo plus sulfasalazine group.

The secondary efficacy outcome was the proportion of patients achieving a response according to the ACR 20\% criteria. At the end of the study, 14/56 (25\%) patients in the leflunomide plus sulfasalazine group were ACR 20\% responders compared with $12 / 50(24 \%)$ in the sulfasalazine alone group, a non-significant difference $(\mathrm{p}=0.543)$. However, significantly more patients in the leflunomide plus sulfasalazine group achieved an ACR 50\% response rate (5/56 $(9 \%))$ compared with the placebo plus sulfasalazine group $(0 \%)(p=0.038)$ (fig $3 \mathrm{~A})$. These results were confirmed in the week 24 completers, where 11/56 (20\%) and 4/56 (7\%) patients treated with leflunomide plus sulfasalazine achieved ACR $20 \%$ and ACR 50\% responses, respectively, compared with $9 / 50$ (18\%) and no patients in the placebo plus sulfasalazine treated patients. However, no significant differences between treatment groups were noted for ACR $20 \%$ response $(p=0.435)$ or ACR $50 \%$ response $(p=0.075)$ in

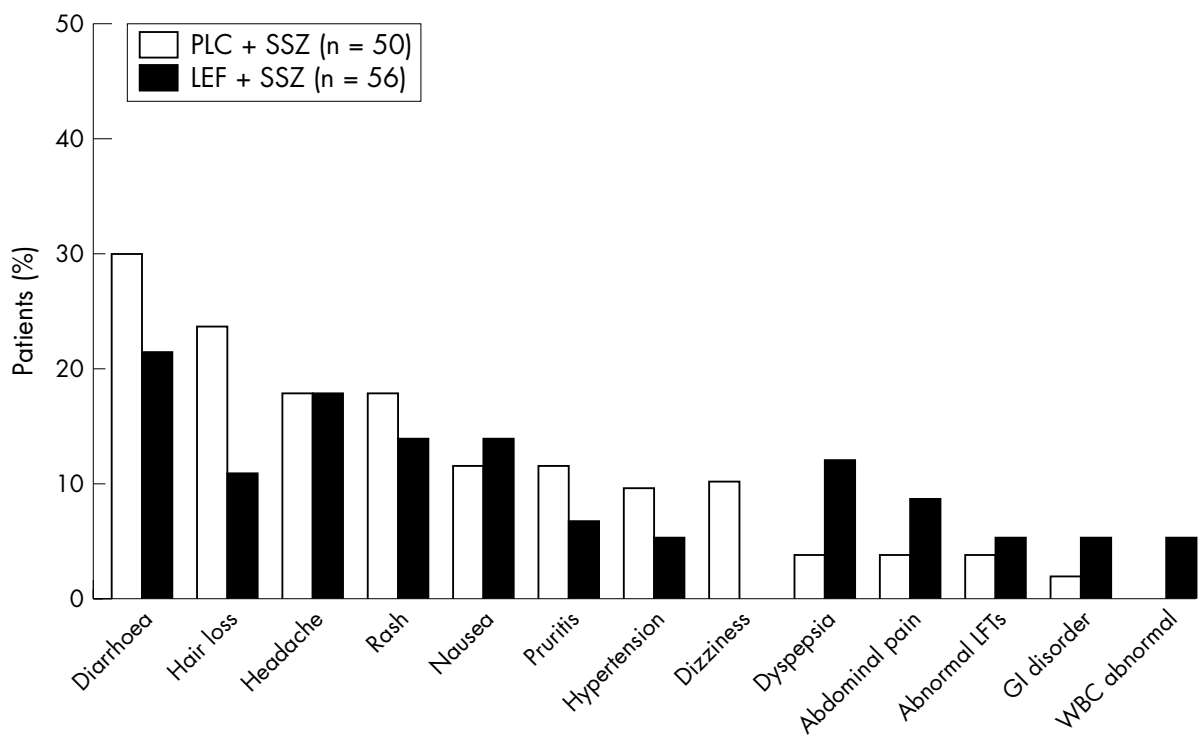

Figure 4 Possibly related adverse events reported in $>5 \%$ of patients. LEF, leflunomide; SSZ, sulfasalazine; PLC, placebo; LFT, liver function test; $\mathrm{Gl}$, gastrointestinal; WBC, white blood cell. 
the week 24 completers. No patients in either treatment group achieved an ACR 70\% response. However, ACR 70\% response rates were achieved in the first open label phase of the RELIEF study, where ACR $20 \%, 50 \%$, and $70 \%$ response rates in the ITT population with LOCF were $66.1 \%, 35.4 \%$, and $10.1 \%$, respectively.

Again, there was a progressive increase in the proportion of patients who were sustained responders according to the ACR 20\% criteria. At week 2, 1/56 (2\%) patients in the leflunomide plus sulfasalazine group and no patients in the placebo plus sulfasalazine group had a sustained ACR 20\% response. These responses were further improved at the end of the study to $14 / 56(25 \%)$ in the leflunomide plus sulfasalazine group and $12 / 50(24 \%)$ in the placebo plus sulfasalazine group (fig 3B).

No statistically significant differences were seen between groups in any of the individual components of the ACR response (table 2 ). The mean changes from baseline in RF levels were $+71.7(812.4) \mathrm{IU} / \mathrm{ml}$ and $-10.4(331.7) \mathrm{IU} / \mathrm{ml}$ in the leflunomide plus sulfasalazine group and placebo plus sulfasalazine group, respectively. The mean changes from baseline in duration of morning stiffness were -0.4 (1.2) hours and +0.01 (1.6) hours in the leflunomide plus sulfasalazine group and placebo plus sulfasalazine groups, respectively.

\section{Safety}

Possibly related adverse events were reported in 41/56 (73\%) patients in the leflunomide plus sulfasalazine group and $38 / 50(76 \%)$ patients in the placebo plus sulfasalazine group. The most common possibly related adverse events were diarrhoea $(21 \%)$, headache (18\%), rash (14\%), nausea $(14 \%)$, and dyspepsia (13\%) in the leflunomide plus sulfasalazine group, and diarrhoea (30\%), hair loss (24\%), headache $(18 \%)$, rash $(18 \%)$, and nausea $(12 \%)$ in the placebo plus sulfasalazine group (fig 4). The incidence of possibly related adverse events was higher (difference $>4 \%$ ) in the leflunomide plus sulfasalazine group than in the placebo plus sulfasalazine group for dyspepsia, abdominal pain, and abnormal white blood cell count. The incidence of possibly related adverse events was higher (difference $>4 \%$ ) in the placebo plus sulfasalazine group than in the leflunomide plus sulfasalazine group for diarrhoea, hair loss, pruritus, hypertension, and dizziness. Possibly related serious adverse events were reported in $6 / 56(11 \%)$ patients in the leflunomide plus sulfasalazine group and $3 / 50(6 \%)$ in the placebo plus sulfasalazine group.

The incidence of possibly related adverse events leading to discontinuation of the study was higher in the leflunomide plus sulfasalazine group $(2 \mathrm{l} / 56(38 \%))$ than in the placebo plus sulfasalazine group $(14 / 50(28 \%))$. The most frequently occurring possibly related adverse events that led to withdrawal were rash ( $9 \% v 8 \%)$, nausea ( $7 \% v 2 \%)$, and diarrhoea $(5 \% \vee 2 \%)$ in the sulfasalazine plus leflunomide group versus placebo plus sulfasalazine group.

\section{Laboratory variables}

Haematology variables showed similar profiles between the two groups, as did liver enzyme tests. One patient in the leflunomide plus sulfasalazine group had abnormally raised liver enzymes $(\geqslant 3 \times \mathrm{ULN})$, although these resolved with continued treatment. Abnormal white blood cell counts of $\leqslant 1.5 \times 109 / 1$ were detected in two patients treated with leflunomide plus sulfasalazine. In one patient the study drug was discontinued and reintroduced with no sequelae of this event, and in the other patient, values normalised on two occasions, before the patient was finally withdrawn owing to a recurrence of this event. In the placebo plus sulfasalazine group, two patients had raised liver enzymes $(\geqslant 3 \times \mathrm{ULN})$; in one of these patients, levels returned to normal and in the other, where levels were $\geqslant 5 \times$ ULN, treatment was discontinued and the patient recovered with no sequelae. A further patient receiving placebo plus sulfasalazine reported mild leucopenia, but this normalised with continued treatment.

\section{DISCUSSION}

This double blind phase of the RELIEF study was performed to evaluate whether the combination of sulfasalazine plus leflunomide was better than sulfasalazine alone for the treatment of active RA for 24 weeks in patients who did not respond adequately to leflunomide. A higher percentage of patients in the ITT population treated with leflunomide plus sulfasalazine $(45 \%)$ than in those treated with placebo plus sulfasalazine (34\%) achieved the primary efficacy end point of a DAS28 response at the end of the study, although this difference was not statistically significant. Despite the small sample size, these responses were similar to the expected DAS28 response rates in both groups. Furthermore, for the week 24 completers, more patients receiving leflunomide plus sulfasalazine $(30 \%)$ than those receiving placebo plus sulfasalazine $(20 \%)$ were DAS28 responders $(p=0.081)$. Comparable numbers of patients in each treatment group were ACR 20\% responders; however, significantly more patients in the leflunomide plus sulfasalazine group achieved an ACR $50 \%$ response rate $(9 \%)$ than in the placebo plus sulfasalazine group $(0 \%)(p=0.038)$. Increasing numbers of patients in both treatment groups achieved sustained DAS28 and ACR 20\% responses-that is, responses that were sustained until the end of the study-throughout the duration of the study. These apparent benefits of the combination must, however, be viewed in light of the fact that there was a higher rate of discontinuance among patients receiving the combination of drugs than in the monotherapy arm (38\% v28\%, respectively).

In general, the responses in both the treatment groups were low and this is probably due to the fact that those patients $(77 \%)$ with a response to leflunomide after 6 months according to DAS28 criteria were not entered into this arm of the trial. This is the first study in which true non-responders to one drug were prospectively analysed for response to a second drug, either in place of, or in addition to, the first drug. In previous trials that investigated the "switch versus add on" question in patients receiving methotrexate, the entry criteria were active disease despite treatment, meaning that partial responders were also included. ${ }^{19}{ }^{21}$ Thus, the true non-responder status in the present study may account for the lower than expected response rates in this double blind phase, and more aggressive treatment may be optimal in these patients.

As there was a higher than expected DAS28 response rate in the first open label phase $(77 \%$ in 6 month completers rather than the expected $50 \%$ ), insufficient numbers of patients were randomised in the double blind phase in order for differences between arms to be assured of being identified by statistical analysis. Only 106 patients were available to enter the double blind study, with 56 receiving leflunomide plus sulfasalazine and 50 receiving sulfasalazine alone, compared with the estimated 146 patients in each treatment arm needed to observe statistical differences. However, a comparison of the observed treatment effects and the expected treatment effects could be considered a relevant technique. In this study the observed treatment effect with leflunomide and sulfasalazine versus sulfasalazine alone $(45 \%-34 \%=11 \%)$ was similar to the expected treatment effect $(50 \%-35 \%=15 \%)$, suggesting that there is a trend for a higher DAS28 response rate by adding sulfasalazine to leflunomide compared with switching to sulfasalazine alone. 
The primary end point in this study-efficacy according to the EULAR criteria using the DAS28 score-classifies patients into groups according to whether they experience good, moderate, or no response to treatment. ${ }^{27}$ In addition, the DAS28 score provides an indication of absolute disease activity. In comparison, the ACR criteria define response as improvement, but do not define absolute disease activity. ${ }^{26}$ However, the two response rate criteria have been shown to have similar validity. ${ }^{27} 28$

The combination of leflunomide plus sulfasalazine had a similar safety profile to that of sulfasalazine alone, with a comparable incidence of possibly related adverse events being reported between groups. The incidence of dyspepsia, abdominal pain, and abnormal white blood cell counts was higher in the leflunomide plus sulfasalazine group than in the placebo plus sulfasalazine group, but these are all adverse events that have previously been associated with leflunomide. No new or unexpected adverse events were seen in the leflunomide plus sulfasalazine group compared with those previously observed in leflunomide treated patients in the first open label phase. Furthermore, there was a similar incidence of serious adverse events in patients receiving sulfasalazine and those receiving leflunomide plus sulfasalazine. The incidence of adverse events leading to study discontinuation was higher in the leflunomide plus sulfasalazine group than in the placebo plus sulfasalazine group, with the most common events leading to discontinuation being rash, nausea, and diarrhoea. Abnormal rises in liver enzymes were only detected in three patients, and in all but one of these cases these levels returned to normal with continued treatment, indicating that leflunomide is associated with a low risk of liver toxicity provided that appropriate monitoring procedures are adopted.

The high numbers of discontinuations in both treatment arms can be attributed mainly to toxicity. The numbers of discontinuations due to toxicity were higher in the leflunomide plus sulfasalazine group than in the placebo plus sulfasalazine group, and this may reflect increased toxicity in the combination arm. However, discontinuation rates were much higher in the placebo plus sulfasalazine group than previously reported in a meta-analysis of controlled clinical trials. ${ }^{29}$ Discontinuations seen in the present study could also be based on the observation that non-responders to one drug, as these patients were, will probably also not respond to another drug. However, the small sample size of this study precludes any definite conclusions about the safety profiles of the compared treatment regimens to be reached.

Leflunomide is known to have a long half life and it may, therefore, have been more appropriate to include a washout period before randomisation in patients entering the double blind phase. This would have effectively removed all traces of leflunomide and ensured the accuracy of the sulfasalazine "alone" group. However, a washout period would have been difficult to apply in this situation, as these patients were already responding poorly and, therefore, required immediate treatment. Trace amounts of leflunomide may explain the lack of difference between the two treatment groups seen over the first 2 months of the double blind phase, but after this time the lack of a washout period should have had minimal impact on the results.

In conclusion, although patient numbers were too small to reach firm conclusions, these results suggest that leflunomide in combination with sulfasalazine provides a reasonable therapeutic alternative to switching to sulfasalazine alone in patients with RA inadequately responding to leflunomide. Therefore, the present study supports the notion that adding a new DMARD to an ineffective one is more effective than discontinuing the ineffective DMARD and switching to a new one. However, further data are needed to demonstrate if the combination of leflunomide plus sulfasalazine can provide a clinically significant benefit.

\section{ACKNOWLEDGEMENTS}

This study was supported by Aventis Pharma.

\section{Authors' affiliations}

M Dougados, Hôpital Cochin, Paris, France

P Emery, University of Leeds School of Medicine, Leeds, UK

E M Lemmel, Max Grundig Clinic, Buhl, Germany

C A F Zerbini, Hospital Heliopolis, São Paulo, Brazil

S Brin, Laboratoire Aventis, Paris, France

P van Riel, University Medical Centre Nijmegen, Nijmegen, The Netherlands

\section{REFERENCES}

1 Anonymous. Guidelines for the management of rheumatoid arthritis: 2002 update. Arthritis Rheum 2002;46:328-46.

2 van der Heijde $D$. Joint erosions and patients with early rheumatoid arthritis. Br J Rheumatol 1995;34(suppl 2):74-8.

3 Emery P, Breedveld FC, Dougados M, Kalden JR, Schiff MH, Smolen JS. Early referral recommendation for newly diagnosed rheumatoid arthritis: evidence based development of a clinical guide. Ann Rheum Dis 2002;61:290-7.

4 Anderson JJ, Wells G, Verhoeven AC, Felson DT. Factors predicting response to treatment in rheumatoid arthritis. Arthritis Rheum 2000;43:22-9.

5 Davis JP, Cain GA, Pitts WJ, Magolda RL, Copeland RA. The immunosuppressive metabolite of leflunomide is a potent inhibitor of human dihydroorotate dehydrogenase. Biochemistry 1996;35:1270-3.

6 Bartlett RR, Anagnostopulos H, Zielinski T, Mattar T, Schleyerbach R. Effects of leflunomide on the immune responses and models of inflammation. Springer Semin Immunopathol 1997; 14:381-394.

7 Fox RI. Mechanism of action of leflunomide in rheumatoid arthritis. J Rheumatol Suppl 1998;53:20-6.

8 Breedveld FC, Dayer JM. Leflunomide: mode of action in the treatment of rheumatoid arthritis. Ann Rheum Dis 2000;59:841-9.

9 Smolen JS, Kalden JR, Scott DL, Rozman B, Kvien TK, Larsen A, et al. Efficacy and safety of leflunomide compared with placebo and sulphasalazine in active rheumatoid arthritis: a double-blind, randomised, multicentre trial. European Leflunomide Study Group. Lancet 1999;353:259-66.

10 Strand V, Cohen S, Schiff M, Weaver A, Fleischmann R, Cannon G, et al. Treatment of active rheumatoid arthritis with leflunomide compared with placebo and methotrexate. Leflunomide Rheumatoid Arthritis Investigators Group. Arch Intern Med 1999;159:2542-50.

11 Emery P, Breedveld FC, Lemmel EM, Kaltwasser JP, Dawes PT, Gomor B, et al. A comparison of the efficacy and safety of leflunomide and methotrexate for the treatment of rheumatoid arthritis. Rheumatology (Oxford) 2000;39:655-65.

12 Kalden JR, Scott DL, Smolen JS, Schattenkirchner M, Rozman B, Williams BD, et al. Improved functional ability in patients with rheumatoid arthritis longterm treatment with leflunomide versus sulfasalazine. J Rheumatol 2001;28: 1983-91

13 Scott DL, Smolen JS, Kalden JR, van de Putte LB, Larsen A, Kvien TK, et al. Treatment of active rheumatoid arthritis with leflunomide: two year follow up of a double blind, placebo controlled trial versus sulfasalazine. Ann Rheum Dis 2001;60:913-23.

14 Cohen S, Cannon GW, Schiff M, Weaver A, Fox R, Olsen N, et al. Two-year, blinded, randomized, controlled trial of treatment of active rheumatoid arthritis with leflunomide compared with methotrexate. Utilization of Leflunomide in the Treatment of Rheumatoid Arthritis Trial Investigator Group. Arthritis Rheum 2001;44:1984-92.

15 Larsen A, Kvien TK, Schattenkirchner M. Slowing of disease progression in rheumatoid arthritis patients during long-term treatment with leflunolmide or sulfasalazine. Scand J Rheumatol 2001;30:135-42.

16 Kalden JR, Schattenkirchner M, Sorensen $\mathrm{OH}$, Emery P, Deighton C, Rozman B, et al. The efficacy and safety of leflunomide in patients with active rheumatoid arthritis; a five-year follow-up study. Arthritis Rheum 2003;48:1513-20.

17 Weinblatt ME, Kremer JM, Bankhurst AD, Bulpitt KJ, Fleischmann RM, Fox RI, et al. A trial of etanercept, a recombinant tumor necrosis factor receptor: $\mathrm{Fc}$ fusion protein, in patients with rheumatoid arthritis receiving methotrexate. N Engl J Med 1999;340:253-9.

18 Kremer JM, Caldwell J, Cannon GW. The combination of leflunomide and methotrexate in patients with active rheumatoid arthritis who are failing on methotrexate treatment alone; a double-blind placebo controlled study [abstract]. Arthritis Rheum 2000;44(suppl):S244.

19 Lipsky PE, van der Heijde DM, St Clair EW, Furst DE, Breedveld FC, Kalden JR, et al. Infliximab and methotrexate in the treatment of rheumatoid arthritis. N Engl J Med 2000;343:1594-602.

20 Weinblatt ME, Kremer JM, Coblyn JS, Maier AL, Helfgott SM, Morrell M, et al. Pharmacokinetics, safety, and efficacy of combination treatment with methotrexate and leflunomide in patients with active rheumatoid arthritis. Arthritis Rheum 1999;42:1322-8.

21 Tugwell P, Pincus T, Yocum D, Stein M, Gluck O, Kraag G, et al. Combination therapy with cyclosporine and methotrexate in severe rheumatoid arthritis. 
The Methotrexate-Cyclosporine Combination Study Group. N Engl J Med 1995; 333:137-41.

22 Kremer JM, Genovese MC, Cannon GW, Caldwell JR, Cush JJ, Furst DE, et al. Concomitant leflunomide therapy in patients with active rheumatoid arthritis despite stable doses of methotrexate. a randomized, double-blind, placebocontrolled trial. Ann Intern Med 2002;137:726-33.

23 Haagsma CJ, van Riel PL, de Rooij DJ, Vree TB, Russel FJ, van't Hof MA, et al. Combination of methotrexate and sulphasalazine vs methotrexate alone: a randomized open clinical trial in rheumatoid arthritis patients resistant to sulphasalazine therapy. Br J Rheumatol 1994;33:1049-55.

24 Dougados M, Emery P, Lemmel EM, Rodriguez de la Serna A, Zerbini CAF Brin S, et al. Efficacy and safety of leflunomide and predisposing factors for treatment response in patients with active rheumatoid arthritis: RELIEF 6-month data. J Rheumatol 2003;30:2572-9.

25 van der Heijde DM, van't Hof MA, van Riel PL, Theunisse LA, Lubberts EW, van Leeuwen MA, et al. Judging disease activity in clinical practice in rheumatoid arthritis: first step in the development of a disease activity score. Ann Rheum Dis 1990;49:916-20.

26 Felson DT, Anderson JJ, Boers M, Bombardier C, Furst D, Goldsmith C, et al. American College of Rheumatology. Preliminary definition of improvement in rheumatoid arthritis. Arthritis Rheum 1995:38:727-35.

27 van Gestel AM, Anderson JJ, van Riel PL, Boers M, Haagsma CJ, Rich B, et al. ACR and EULAR improvement criteria have comparable validity in rheumatoid arthritis trials. American College of Rheumatology European League of Associations for Rheumatology. J Rheumato 1999:26:705-11.

28 Villaverde V, Balsa A, Cantalejo M, Fernandez-Prada M, Madero MR, Munoz-Fernandez S, et al. Activity indices in rheumatoid arthritis. J Rheumatol 2000;27:2576-81.

29 Felson DT, Anderson JJ, Meenan RF. The comparative efficacy and toxicity of second-line drugs in rheumatoid arthritis. Results of two metaanalyses. Arthritis Rheum 1990;33:1449-61.

\section{Clinical Evidence - Call for contributors}

Clinical Evidence is a regularly updated evidence-based journal available worldwide both as a paper version and on the internet. Clinical Evidence needs to recruit a number of new contributors. Contributors are healthcare professionals or epidemiologists with experience in evidence-based medicine and the ability to write in a concise and structured way.

Areas for which we are currently seeking authors:

- Child health: nocturnal enuresis

- Eye disorders: bacterial conjunctivitis

- Male health: prostate cancer (metastatic)

- Women's health: pre-menstrual syndrome; pyelonephritis in non-pregnant women

However, we are always looking for others, so do not let this list discourage you.

Being a contributor involves:

- Selecting from a validated, screened search (performed by in-house Information Specialists) epidemiologically sound studies for inclusion.

- Documenting your decisions about which studies to include on an inclusion and exclusion form, which we keep on file.

- Writing the text to a highly structured template (about 1500-3000 words), using evidence from the final studies chosen, within 8-10 weeks of receiving the literature search.

- Working with Clinical Evidence editors to ensure that the final text meets epidemiological and style standards.

- Updating the text every six months using any new, sound evidence that becomes available. The Clinical Evidence in-house team will conduct the searches for contributors; your task is simply to filter out high quality studies and incorporate them in the existing text.

- To expand the topic to include a new question about once every 12-18 months.

If you would like to become a contributor for Clinical Evidence or require more information about what this involves please send your contact details and a copy of your CV, clearly stating the clinical area you are interested in, to Klara Brunnhuber (kbrunnhuber@ bmigroup.com).

\section{Call for peer reviewers}

Clinical Evidence also needs to recruit a number of new peer reviewers specifically with an interest in the clinical areas stated above, and also others related to general practice. Peer reviewers are healthcare professionals or epidemiologists with experience in evidence-based medicine. As a peer reviewer you would be asked for your views on the clinical relevance, validity, and accessibility of specific topics within the journal, and their usefulness to the intended audience (international generalists and healthcare professionals, possibly with limited statistical knowledge). Topics are usually 1500-3000 words in length and we would ask you to review between 2-5 topics per year. The peer review process takes place throughout the year, and our turnaround time for each review is ideally 10-14 days.

If you are interested in becoming a peer reviewer for Clinical Evidence, please complete the peer review questionnaire at www.clinicalevidence.com or contact Klara Brunnhuber (kbrunnhuber@bmigroup.com). 